\title{
De la alegoría de las aves en Tratado sobre la monarquía columbina, del padre Andrés Merino de Jesucristo*
}

\author{
Claire Mercier ${ }^{1}$ \\ Universidad de Chile (Chile)
}

\section{Resumen}

En este estudio analizaremos la figura alegórica de las aves en el Tratado sobre la monarquía columbina (1790), del padre Andrés Merino de Jesucristo. Estableceremos, en primer lugar, el lazo entre alegoría y tradición de la emblemática, lo que permitirá abrir el campo a la figura del príncipe, a fin de establecer una relación con el género de los tratados de buen gobierno, respecto a la presentación de una forma de monarquía ideal. A continuación, estudiaremos la composición de esta sociedad utópica, es decir, la alegoría y la utilización de la figura de las aves, sobre todo, en relación con la tradición de los bestiarios cristianos de la Edad-Media. Finalmente, analizaremos la utilización satírica de esta figura, dentro de la perspectiva contra-utópica de la obra, lo que permitirá en-

\section{Abstract}

This study approaches the analysis of the allegorical figure of the birds, in the "Tratado sobre la monarquía columbina", by father Andres Merino of Jesus Christ (1790). First, the link between allegory and the tradition of the emblematic will be established, exhibiting the figure of the prince. As a result, a relationship with the genre of the treatises of good governance, with respect to the presentation of a monarchy as an ideal, will be ascertained. Next, the composition of this utopian society will be studied, that is, the use of allegory and the figure of birds, above all in relation to the tradition of Christian bestiaries in the Middle Ages. Finally, the satirical use of this figure in the antiutopian perspective of the work will be analyzed, which will then

\footnotetext{
* From the allegory of the birds in the Tratado sobre la monarquía columbina. Recibido: Abril, 2011 - Aprobado: Mayo, 2011.

${ }^{1}$ Estudios literarios en el Liceo Católico Saint-François (Francia) y en Letras Modernas de la Universidad de Savoie (Francia). Magister en Literatura Francesa, Extranjera y Comparada de la Universidad de Savoie y Doctora en Literatura, con mención en Literatura Chilena e Hispanoamericana de la Universidad de Chile. e-mail: claire-mercier@live.fr
} 
tonces identificar una crítica de la sociedad española del siglo XVIII.

Palabras clave: alegoría, emblemática, tratados de buen gobierno, iluminismo, sátira contra-utópica. identify a critique of eighteenth century Spanish society.

Key words: allegory, emblematic, treatises of good government, Enlightenment, anti-utopian satire.

\section{Introducción}

Es un presupuesto común considerar la producción literaria utópica española del siglo XVIII como prácticamente inexistente. No obstante, como señala José Luis Abellán (1986), en su Historia crítica del pensamiento español, esta consideración sería consecuencia de una "falta de investigación sistemática y de una lectura inadecuada de los textos" (609). Con esto, Abellán expresa la necesidad de un estudio más adecuado y más completo de los textos, dentro de los cuales destaca una obra: Tratado sobre la monarquía columbina (1790), del Padre Andrés Merino de Jesucristo (1730 - 1787).

Dentro del género se conoce más la utopía clásica Sinapia (s.XVII), pero con el Tratado sobre la monarquía columbina entramos en algo diferente e inusual, al considerar esta fresca histórica de la nación palomar en veintitrés páginas como una construcción textual no tradicional para su época. La principal razón es que el texto del padre Merino se constituye como una contra-utopía que critica ciertas modalidades del Iluminismo. Por esta razón, decidimos emprender el estudio de una obra relativamente desconocida para aportar esperamos- al fortalecimiento de una nueva huella de la literatura utópica española dieciochesca.

\section{Presentación de la obra}

Tratado sobre la monarquía columbina se divide en cuatro partes, bajo la denominación de "discursos". El primer discurso presenta una comunidad de palomas ejemplares, con un natural "sencillo é inocente" (1790: 61). A causa de la persecución de las "aves de rapiña", deciden buscar un nuevo lugar para vivir. Durante una tempestad nocturna, encuentran como refugio una caverna, donde la más antigua de las palomas, Calistomos -símbolo de la comunidad-, toma la palabra, a fin de exponer la situación actual de las palomas, 
así como también su proyecto futuro. En efecto, las aves de rapiña, consideradas como el deshonor del género volátil, han tomado el poder mediante una revolución. Sin embargo, existe, "junto a la Ciudad del Sol" (que es una clara referencia a la Civitas Solis [1602] de Campanella), un país de paz, gobernado por la reina de las aves, "la ave Fénix": "Crisorróa". Aquí está el lugar utópico, "donde goza de una tranquilidad y felicidad" (64) y "adonde todo lo bueno abunda" (61-70).

El segundo discurso relata el viaje y la llegada al país utópico y la consiguiente muerte de la mitad de las palomas por un proceso de selección de las mejores. El discurso tercero expone las pocas leyes de la monarquía, pues, al tratarse del mundo ideal de la utopía, no se necesitan muchas reglas. Así, existe una organización social en "tribus o barrios" (71), una predominancia de la agricultura y el ideal de una sociedad igualitaria: "Allí, todo se dio por común, nada se reservó ni privilegió; no había jerarquías, y por lo mismo no ambición de los honores" (71). Las leyes son enunciadas por el pelícano Argidoroto y divididas en artículos.

El discurso cuatro concluye con el fracaso del proyecto utópico. La narración hace un salto temporal de quinientos años: antes de morir, la reina intenta establecer la paz entre las aves de rapiña y las palomas. De las cenizas de la reina nace un "polluelo": Morantia. Las aves se presentan al nuevo rey como gente "ilustrada y civilizada" (81). Las palomas se dejan convencer por el discurso y autorizan a las aves de rapiña a entrar en la Provincia Columbina. Poco a poco, éstas reproducen su propio tipo de gobierno, con la creación de una jerarquía y de tribunales. Instalan, además, universidades y escuelas, introduciendo profesores del extranjero. El proceso, sin embargo, es todo lo contrario de una iluminación. Las aves ilustradas se convierten en aves rapiña y "crecían los tributos" (83). Entonces, se observa una persecución a la clase inferior (las palomas), que, sin embargo, mantiene económicamente a la clase "superior" (las aves). Existen también aves letradas, aves arpías, buscando la felicidad de las palomas, pero al fin "solo hacían feliz a su buche" (84). El texto concluye con la siguiente moraleja: "Las palomas, por último, escaparon a las Ciudades de los hombres, y huyendo de unos enemigos, dieron en poder de otros peores" (84).

\section{Una alegoría emblemática}

Como figura alegórica, las aves, en el Tratado sobre la monarquía columbina, pueden ser consideradas bajo la tradición, igualmente 
simbólica, de la emblemática. Según la definición de Santiago Sebastián (1995), en Emblemática e historia del arte, ésta es "una figura simbólica, que tiene un título y va seguida de un epigrama, con el fin de enseñar o moralizar" (12). Ante todo es una figura gráfica, pero que contiene una perspectiva literaria, considerando al título y al texto. El historiador español agrega: "El emblema en su esencia cumple dos funciones básicas: la representación y la interpretación, es decir, representa una cosa (res pictura), que es algo de la naturaleza, del arte, de la mitología, de la religión, etc., que llega a ser res significans como expresión de una verdad" (12).

Así, la emblemática también se basa en la alegoría, a través de una representación indirecta, pero con el adjunto de un sentido suplementario. Se trata entonces del mismo procedimiento con la figura de las aves en el Tratado sobre la monarquía columbina, como alegoría dotada de toda una simbología establecida, pero que en su propio contexto empírico obtiene una nueva dimensión, una nueva verdad. Por ejemplo, las palomas son la alegoría tradicional del Espíritu Santo, de la paz y la inocencia, pero, como vamos a verlo, al figurar al pueblo oprimido en camino hacia su tierra prometida (la monarquía columbina) pueden representar al pueblo hebreo (en un registro cristiano), o más precisamente, a la clase popular y campesina (en el contexto del siglo XVIII), hambrienta por las acciones de los nobles (las aves de rapiña).

La emblemática cuenta con toda una tradición política, sobre todo en la pintura barroca española del siglo XVII: vemos los retratos emblemáticos de los reyes españoles, con la manifestación de su poder y la mostración de sus atributos (sus emblemas) ${ }^{2}$. Esta misma figura del príncipe nos permite abrir el Tratado sobre la monarquía columbina al género de los tratados de buen gobierno, definido según R. W. Truman (1999) como:

[...] for the most part they are untechnical in character and in the main present themselves as discussions giving statement not to intellectual theories but to convictions and aspirations or lines of personal interest -convictions and aspirations regarding the purpose and values to be pursued and cherished either by the ruler or by civics official or by society at large or by individuals within that society (8).

\footnotetext{
${ }^{2}$ Pensando, sobre todo, en los retratos "a caballo" de Diego Velásquez: los de Felipe IV o del Príncipe Baltasar Carlos.
} 
En efecto, muchos emblemistas, como Saavedra o Solórzano (Emblematica centum, regio política, 1653), tuvieron como referente para sus obras la figura del príncipe ${ }^{3}$, respecto a la importancia de su educación y de su formación para su cargo futuro. La misma imagen del príncipe permite operar el nexo entre la emblemática y el género del speculum principum, como los trabajos de Diego Saavedra Fajardo, quien redactó un tratado de buen gobierno bajo el título de Las empresas políticas. Idea de un príncipe político-cristiano representada en cien empresas (1640). Si entendemos el Tratado sobre la monarquía columbina como una alegoría, podemos relacionarlo con la tradición de la emblemática, lo cual permite que, además, lo vinculemos con los tratados de buen gobierno en la exposición de una monarquía ideal.

En el contexto de la obra, la concepción del príncipe se orienta hacia la figura de un monarca ilustrado y gobernando con ayuda de la Razón: el despotismo ilustrado. Es una doctrina política del Iluminismo basada en una alianza del poder monárquico y la filosofía (con el modelo del filósofo-rey de la Republica de Platón), para un gobierno guiado por el principio de la Razón. Tuvo intentos reales, como ocurrió con Diderot y Catalina II de Rusia, o Voltaire y Federico II de Prusia. En paralelo a esta doctrina, se opera un proceso de reforma "racional" dentro de la Europa del siglo XVIII, como ocurre en el dominio de la economía con la modernización de la industria u organización administrativa del Estado: una mejor repartición de las tierras agrícolas y una reorganización de las estructuras religiosas bajo el principio de tolerancia.

En el contexto español, estas propuestas de gobierno se concretizan bajo el reino de Felipe IV, al igual que en el de Carlos III, a partir del reformismo borbónico, cuyo objetivo principal fue rescatar una monarquía en crisis. Según Abellán (1986), esto se materializó con reformas "que tendieron, principalmente, al regalismo eclesiástico, a la liberación económica, al centralismo y a la unificación administrativa" (472). Por ejemplo, una reforma de la educación bajo el poder real, entonces al servicio del Estado (sobre todo en contra de los jesuitas): "el trono ha de ser el dispensador y el orientador de la cultura [...]. Ante todo, porque la tarea es de tal envergadura, que solo la autoridad y el poder del monarca pueden llevarla a feliz término" (Sarrailh, 1957: 189). La institución real debe ser ella misma un reflejo ideal de tal aspiración, exponiendo los principios de justicia y honradez a través de la figura del príncipe.

\footnotetext{
${ }^{3}$ Según la etimología latina: princeps, el soldado de la primera línea, o más precisamente en este contexto, el principio director y reflejo "promocional" del gobierno.
} 
Esto se da también mediante el regalismo, es decir, el restablecimiento del poder de la monarquía a la que Roma ha desposeído de sus derechos. La crítica se dirige hacia una Iglesia rica y supersticiosa, mientras que se valoriza un cristianismo más interior, con un retorno a los valores de la bondad y la fraternidad. Se trata, además, de una valorización del Estado, de una promoción nacional. Sarrailh señala: "Este regalismo es la afirmación de la autoridad real, plenamente aceptada por todos" (600), lo que también expresan otros autores como Freijoo, quien ya en el título del ensayo "Amor de la patria y pasión nacional", manifiesta una valoración semejante: "En verdad, nadie habla en España de despotismo o de absolutismo. Los hombres de la minoría ilustrada están convencidos de que viven bajo una monarquía moderada y casi liberal" (citado por Sarrailh, 579). Lo anterior explica la conservación de la monarquía en España, a diferencia de lo ocurrido en Francia.

En la primera página del Tratado sobre la monarquía columbina se encuentran juntas las denominaciones de "monarquía" y "republica". No se debe olvidar que la monarquía puede constituirse como tal por la elección de mejores de la sociedad (que es una aristocracia también). Para la imagen del representante del régimen, se puede ver que la figura del monarca es bien desarrollada en la obra de Merino con la Reina Fénix, constituyéndose en metonimia del gobierno, debido a que es "compasiva y liberal" (65), "benigna y discreta" (70). La reina no comparte, sin embargo, el ideal de colectividad de la figura del buen príncipe ante todo ciudadano ideal involucrado en la sociedad, ya que es "muy amante de la soledad [...] por no ver las maldades que ejecutan los piratas con los inocentes" (70).

La obra comparte el lado de la promoción nacional, de la conservación de una "identidad" y de un estado mediante la mostración de la esfera perfecta de la utopía. En este sentido, la obra de Andrés Merino hace constantemente referencia al miedo del retorno de las aves de rapiña, figura del vicio, que al final de la obra destruyen la monarquía ideal. El modelo de la monarquía ilustrada se mezcla, igualmente, con el ideal utópico de la "inocencia, paz, humanidad y tranquilidad", con una ausencia parcial de leyes y el ideal de una sociedad igualitaria: "yo no necesito de vuestros sudores y trabajos para la ostentación ni alimento de mi Palacio"; "Allí, todo se dio por común, nada se reservó ni privilegió; no había jerarquías, y por lo mismo no ambición de los honores" (71).

Sin embargo, respecto a la mención del país utópico como el de un paraíso, y con la crítica de una cierta forma del Iluminismo, parece que la idea utópica aquí es la del retorno a una Edad de Oro, con el 
descubrimiento del paraíso terrenal perdido ${ }^{4}$, pero inscribiéndose todavía en un cierto canon del género utópico dieciochesco:

El carácter restauracionista que con frecuencia reviste la utopía -la añoranza de la Edad de Oro, la vuelta a la sociedad primitiva-, junto a su casi inevitable deriva igualitaria, explica la indiferencia de una parte de los philosophes hacia un concepto que parecía contrario al sentido progresivo y reformista del proyecto ilustrado (Fuentes, 1998: 133).

Esto explicaría la ausencia del término "utopía" en la Encyclopédie, de Diderot y de Alembert. No obstante, el nexo permanece con la tradición de los tratados de buen gobierno como referente teórico de la constitución literaria de la utopía. Ejemplo de ello son Platón (Republica, s. IV a.C), Tomás Moro (Dialogue of Confort against Tribulacyon, 1534) y Tommaso Campanella (De la monarchia hispanica discursus, 1601), quienes redactaron tratados de buen gobierno como suplemento teórico a sus obras utópicas.

Ello nos permite finalmente pensar la heterogeneidad genérica como un rasgo propio del género utópico en el siglo XVIII, con el Tratado sobre la monarquía compartiendo el lado utópico y contra-utópico, el de los tratados de buen gobierno, la alegoría y la emblemática literaria, pero también la literatura de viaje. El relato del padre Merino, sin embargo, no presenta la forma clásica del viaje utópico. Es decir, el relato laudatorio del descubrimiento de una sociedad ideal por un viajero ${ }^{5}$. Pero como utopía, esta obra invita al lector a efectuar el viaje imaginario al "no lugar", lo que se encuentra de nuevo en el texto mismo, en una puesta en abismo con el viaje que las palomas efectúan hasta la ciudad ideal.

Como alegoría, Tratado sobre la monarquía columbina se acerca a la tradición de la emblemática, que nos permite considerar la obra, con la figura del príncipe, como representación del modelo contextual de la España del siglo XVIII, del despotismo ilustrado y el género de los tratados de buen gobierno, mezclado con el proyecto utópico que la dirige más hacia el deseo del retorno a una Edad de Oro.

\footnotetext{
${ }^{4}$ Acercándose a la tradición literaria de la Edad-Media, de la literatura de la búsqueda del paraíso terrenal, con el ejemplo del Roman d'Alexandre o del Voyage de Saint-Brandan.

5 Basándose, por supuesto, sobre los descubrimientos geográficos y sus repercusiones en el imaginario colectivo (la visión de América como la de un nuevo Edén), pero también, sobre el suceso literario de los propios relatos de viaje de los exploradores.
} 


\section{De la alegoría de las aves}

La figura de las aves y la composición de una sociedad volátil se construyen sobre un díptico, con la división entre las palomas (quienes formaron antiguamente parte del cuerpo volátil en general) y las aves de rapiña. La distinción recobra el maniqueísmo entre el universo de la virtud y del vicio, lo que corresponde a la alegoría general de las aves, como la de las almas. En efecto, primero, la paloma está asociada a la imagen del Espíritu Santo (y más generalmente del alma), de la inocencia, la pureza y de la paz. Éstas se presentan al principio del primer discurso con un "natural sencillo é inocente" (61).

Podemos decir que la alegoría de la paloma tiene un referente cristiano que logra la asimilación con Jesucristo: "el hijo separado del padre, y la madre de las queridas prendas de sus entrañas" (61). Las palomas, por ejemplo, huyen a un desierto antes de alcanzar el país utópico, donde, en un real proceso de selección, la mitad de ellas muere. Eco del episodio de los cuarenta días y noches de Jesucristo en el desierto, a fin de confrontarse con la tentación del Diablo. Podría también hacer referencia al pueblo elegido: los hebreos guiados por Moisés (con el papel y la imagen de la más antigua de las palomas, Calistomos ${ }^{6}$ ), a través del desierto, hasta la tierra prometida, o al episodio de Noé, con la simbólica de la paloma con el ramo de olivo como guía divino ${ }^{7}$.

Es de notar que se requieren seis días para llegar al país utópico, lo que podemos relacionar con todo lo que el número seis simboliza en el registro cristiano (símbolo de la perfección: de la creación del mundo en seis días). Siguiendo la alegoría, las palomas ocupan el papel de víctimas, de mártires, frente a las aves de rapiña, de las cuales se dice: "engorden con nuestra sangre" (63), ya que "la naturaleza no nos dio armas alguna para nuestra defensa" (64). Es posible, así mismo, ir más lejos con la semejanza entre las características de las palomas y el lugar utópico, lo que implica pensar la sociedad utópica como un ideal de igualdad, de moderación e inocencia, al presentársenos como una Edad de Oro, un estado natural no pervertido (la "templanza y honestidad con que vivieron en tiempos antiguos [...] abuelos y bisabuelos" [63]). Se aludiría también a la clase popular del contexto empírico de la obra, frente a la avaricia y la "ilustración" de la clase dominante de las malas aves.

\footnotetext{
${ }^{6}$ Tiene su doble, al final del relato, llamado Sofotatos, haciendo quizás eco a la figura de la Razón, vía referencia a Sófocles, considerando consonancia de los dos nombres. 7 “[...] los fieles en busca de refugio en Cristo" (Cooper, 2007: 137).
} 
En el pasado existían las "aves" en general, situadas temporalmente antes de la revolución efectuada por las aves de rapiña: tiempo donde el cuerpo volátil era unido e ilustre (la Edad de Oro Volátil): "nobles, como son águilas, buitres, gavilanes, milanos, azores, neblíes, gerifaltes, sacres, quebrantas, huesos, harpías, vencejos, búhos, cornejas, lechuzas, mochuelos" (62). Si seguimos sosteniéndo las semejanzas que hemos comenzado a desarrollar, podemos recurrir a la tradición de los bestiarios de la Edad Media, con el fin de entender la alegoría detrás de cada figura ${ }^{8}$. El águila es la figura de una juventud eterna, de un bautismo sin fin, ya que, según la profecía de David, como cuenta el bestiario de El fisiólogo (1971): "Se renovará tu juventud como la del águila" (147)9. El águila es el rey de las aves, lo que establece un nexo con la figura del Cristo y los ángeles. Su principal característica es la visión, o a un nivel más simbólico, la clarividencia ${ }^{10}$.

La figura del milano se confunde con frecuencia con la del águila, como ave real. El buitre es el ave que precede a la muerte, pero en el Tratado sobre la monarquía columbina está considerado como un ave noble. En el Egipto Antiguo, era un símbolo positivo: la imagen de la transmutación de la muerte en la vida. Hace referencia, además, a la Virgen María, ya que, como una vez más consigna El fisiólogo, se dice que con la piedra "eutocia", la hembra pare sin dolor y sin la intervención de un varón (171).

En cuanto al gavilán, como lo menciona el Bestiario medieval de Ignacio Malaxecheverría (1999), forma parte de las aves que no pueden volar. Por lo tanto, se muestra como alegoría del hombre humilde, sufrido y piadoso, que siempre mira al cielo de su redención. Esta alegoría, no obstante, es aquí un poco contradictoria, porque, como ave para la caza, es susceptible de ser considerado como noble, y al mismo tiempo, percibida como ave de rapiña a causa de sus garras.

El búho, como ave nocturna, tiene una connotación positiva: "Así también Nuestro Señor Jesucristo amó más a los que yacíamos en tinieblas y en la sombra de la muerte, al pueblo de los gentiles, que al pueblo de los judíos que habían recibido la adopción y que habían

${ }^{8}$ Justificamos el uso de los bestiarios cristianos de la Edad-Media por las características católicas de la Ilustración española, lo que se nota también mediante la trama del relato y la elección de ciertas aves, como por ejemplo la paloma.

${ }^{9}$ El águila como alegoría del Cristo y de un bautismo eternal, ya que cuando siente su vista disminuir y la viejez acercarse, se sumerge en el agua tres veces a fin de volver a ser joven.

${ }^{10}$ Puede ser también una alegoría del Anticristo (el águila bicéfala), como ave rapaz. 
tenido antes la promesa de herencia de los padres" (El fisiólogo, 144145). La corneja, como ave monógama, es un símbolo de fidelidad.

Todo este cuerpo volátil vivía en una Edad de Oro: "un tatarabuelo mío aseguró haber vivido juntamente con un sacre muy inocente" (63), antes de la separación de la nación volátil en dos. La reina de las aves, Crissoroa -el ave Fénix-, representa la imagen del Cristo en la cruz, su sacrificio por los hombres y su resurrección (sacrificio que ella hará, pidiendo la paz entre las aves y las palomas, antes de morir como mártir): "el fénix es una imagen de nuestro Salvador" (El fisiólogo, 150). El fénix vive quinientos años, lo que "significa en sentido moral un término de perfección" (Malaxecheverría, 1999: 176). Como dueña del paraíso terrenal, "compasiva y liberal" (65), "benigna y discreta" (70), la reina Crissoroa, en la obra del padre Merino de Jesucristo, corresponde al ideal utópico: guía de las aves, ya que en su reino se "gozará de las inocentes delicias que quiso el creador fuesen propias de sus criaturas" $(65)^{11}$. Otra ave famosa, perteneciente al lugar utópico, es el pelícano, allí llamado Argidoroto, y secretario de la Reina. Es también una alegoría del Cristo ${ }^{12}$, ya que:

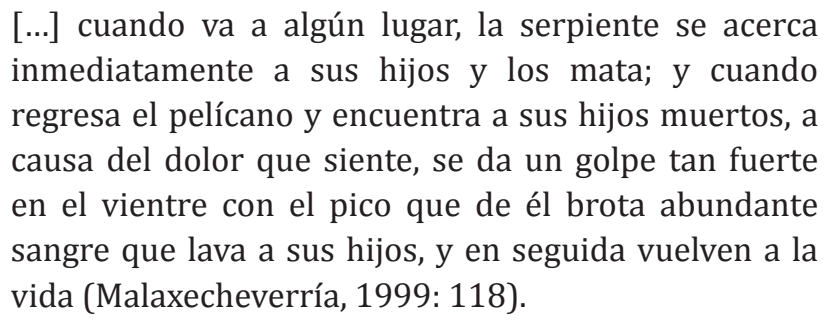

Representa, al igual que el fénix, el sacrificio del Cristo para sus hijos. La garza hace parte, así mismo, de este cuerpo que, a un nivel alegórico, como ave de agua, representa el bautismo y a Cristo. El cisne, por su parte, es caracterizado en los bestiarios por la belleza de su canto antes de morir, lo que simboliza al hombre virtuoso que no teme a la muerte. Destaca igualmente su simbólica de fertilidad.

En cuanto a las aves separadas del cuerpo volátil, como alegoría de la introducción del vicio en el mundo utópico de las palomas, sus principales características son la avaricia y la corrupción de la sociedad igualitaria de la utopía y del estado natural de la antigua

\footnotetext{
${ }^{11}$ Cabe anotar que en el Dictionnaire des simboles, el fénix es presentando como doble femenino del dragón (1982: 747).

12 "suspendido en la altura de la cruz y abriendo su propio costado, nuestro Salvador derramó la sangre y el agua para la salvación y la vida eterna” (El fisiólogo, 1971: 144).
} 
Edad de Oro. Aves de rapiña, "piratas" y "ladrones" (61), a este cuerpo pertenecen los milanos, los búhos y las lechuzas: grupo constituido por un ave rapaz, ávida de sangre ("que nunca se saciaban de su sangre" [61]) y dos aves nocturnas que tienen una connotación peyorativa, en oposición a la luz celeste. Corrompidas por el contacto con el extranjero, con la mención, en un registro exótico, de "los papagayos Nordestes, y guacamayos de Indias" $(63)^{13}$. Al contrario de la alegoría popular de las palomas explotadas, las aves de rapiña representarían la clase dominante o nobleza. En razón al campo lexical de las aves, su deshonestidad está simbolizada por su vuelo: "volar al derecho, al revés, hacia arriba, hacia abajo, de lado, y de espalda" (64). Cada ave, al final del relato, ocupará una función dentro de la Provincia Columbina:

[...] señalando por Chiliarco a los buitres hecatontareos, los quebranta huesos Bonletos, los milanos Abogados, y Relatores los sacres y neblíes. Alcaldes y Alguaciles gavilanes, gabilancetes Verdugos y Pregoneros los vencejos, y para guardar los caminos por la noche, los búhos, lechuzas, mochuelos y cornejas. Para las academias buscaron aves, trajeron aves de Indias, como guacamayos y papagayos; para letras menores y retóricas, cotorras y maricas; las jerarquías se dieron a los cisnes, onocrótalos y pelícanos: y también crearon caballeros a algunos palomos de los áulicos (82).

Los puestos administrativos son ocupados por las aves más o menos nobles; la guardia de noche, por las aves nocturnas. Las funciones educativas son dispensadas por las aves exóticas, y las nobles, por las aves más ilustradas, que pertenecían a la antigua sociedad utópica palomar -tenemos aquí una notable jerarquía de valores que resume la distinción entre las aves-, y finalmente se introdujeron "gorriones, jilgueros, tordos, perdices, chochas, codornices" (82). Es decir, aves de más pequeño tamaño y aves arpías, todavía en una connotación peyorativa, respecto a su tamaño y a su "función" natural.

En esta misma división tenemos la figura de Judas con la paloma llamada Polirróa, "que había contraído parentesco con un gavilán" (66) y que defendió, durante el discurso de Calistomos en la caverna ${ }^{14}$,

\footnotetext{
${ }^{13}$ Vale preguntarse si este registro del extranjero no sería una analogía de los conquistadores de América.

${ }^{14}$ Preguntándose si existiría una relación con el mito y/o alegoría de la Caverna de Platón, con un paralelo entre el camino hacia la luz de la verdad y hacia el lugar utópico.
} 
a las aves de rapiña en términos de aves "ágiles, civilizadas, diestras, industriosas y vividoras" (66). Esta permitió la entrada de los milanos reales a la caverna con el objetivo de matar a las palomas. Existe también otra paloma, Cacoteros, que hace la promoción de las aves cuando, al final del relato, entran en la Provincia Columbina con la intención de reproducir su propio tipo de gobierno.

Tenemos, por lo tanto, la construcción de una verdadera jerarquía de las aves en Tratado de la monarquía columbina, pertenecen unas al campo del Bien (con las palomas, aves de la antigua Edad de Oro que conformaban el lugar utópico) o del Mal (con las aves de rapiña). Todas las figuras tienen una clara característica alegórica respecto a una figuración cristiana.

\section{Una alegoría satírica}

La figura de las aves se inscribe en una tradición satírica, particularmente en conexión con Las aves (s. V a.C.), de Aristófanes. Relata la comedia griega la historia de dos atenienses (Pisthétaïros y Evelpidès) que deciden huir de la polis y convencen a los pájaros de fundar una nueva ciudad ideal entre los hombres y los dioses (aludiendo una vez más a la perspectiva del género de los tratados de buen gobierno). Aristófanes realiza primero una parodia del movimiento místico de los órficos (tomando como referencia la figura de Orfeo), para los que el mundo proviene de un huevo; luego exprime su desilusión, refiriéndose a la próxima guerra de Atenas contra Sicilia (debemos recordar que la obra de Aristófanes que precede a Las aves se titula La paz.

Dibuja la obra una sátira contra los ciudadanos de Atenas desde los diferentes personajes que se presentan a la nueva ciudad, pero que se encuentran rápidamente rechazados por ella. Al final, se hace visible la sátira contra los dioses, quienes capitulan, reducidos al hambre por las aves. Pisthétaïros es, pues, elegido como dios de los dioses. La obra presenta, en este sentido, la construcción de un paraíso perdido (una utopía) entre la tierra y el cielo. Encontramos casi las mismas aves que en Tratado sobre la monarquía columbina ${ }^{15}$. Las aves elegidas son las más pequeñas del bosque, reputadas por su canto. Como es lógico, la alegoría alude a las divinidades de la Antigüedad (diferenciándose de la cristiana). Tenemos a la corneja,

\footnotetext{
${ }^{15}$ Nos centráramos únicamente en las aves presentes en el Tratado sobre la monarquía columbina, presentando su simbólica propia (Chevalier \& Gheerbrant, 1982).
} 
símbolo de fidelidad, y a la lechuza, ave nocturna: alegoría de Atenas. El milano y el gerifalte son asociados a Apolo, como símbolos de clarividencia. El águila representa a Zeus, y es un símbolo de realeza y clarividencia. Vemos, además, aves sin un claro simbolismo, como el búho, alegoría de la solitud y la tristeza y mensajero de la muerte.

Están presentes también el pelícano, desprovisto de su alegorización cristiana, la garza, la grulla, la cigüeña, la golondrina y el buitre (este último alegoría una vez más de Apolo, y considerado como ave adivinatoria, tal como ocurre en el mito de Rómulo y Remo) ${ }^{16}$. El gavilán, por su parte, no representa a ningún dios, pero es como el águila, un símbolo de realeza. Y por último, el ibis, el tordo, la oca (ave de Juno) y la paloma (de Afrodita), alegoría del amor.

Los diferentes cuerpos de la obra están bien delimitados. Por una parte, están los hombres (los malos ciudadanos de Atenas), los dos héroes de la comedia (que en un momento se disfrazan en aves) y los dioses. Por otra, las aves y las medio-aves (como Térée-Lahuppe, un hombre transformado en ave e intermediario entre el mundo volátil y el de los humanos). El lugar utópico es poco descrito; pero, como pasa en el Tratado sobre la monarquía columbina, tiene la característica de la naturaleza fértil y abundante, imagen del paraíso terrenal. Asistimos en la comedia del griego a un intento de perversión de la ciudad ideal para los hombres (el sacerdote, el poeta, el inspector, etc.), con el rechazo del principio de una organización administrativa, respecto a las diferentes funciones que ocupan los hombres.

Como en la contra-utopía española, las aves tienen el papel de víctimas, ya que son utilizadas para los sacrificios. Se hace también referencia en Aristófanes a una antigua Edad de Oro, ubicada en los tiempos de la mitología, presentando un ave (una alondra) como el primero de los seres, y un papel antiguamente más honorífico, con el águila, alegoría de los reyes (Menelao o Agamenón), o las aves que representan a dioses (Hermes, Afrodita, etc.). La sátira opera a través de juegos de palabras que permiten asociar, en un proceso de animalización, las características de las aves a las de hombres y dioses (Artemis, ya no diosa de la caza, pero sí de las zancudas [76]).

La dimensión satírica de las alegoría de las aves de Merino permite considerar la perspectiva crítica de la obra en relación con la sociedad española del siglo XVIII, observando que "las formas sucesivas de la utopía están estrechamente vinculadas al origen

${ }^{16}$ El cisne, símbolo de pureza, es también una de las numerosas aves alegoría de Apolo. 
con determinadas etapas de desarrollo, y en cada una de éstas con ciertas capas sociales" (Mannheim, 1941: 181). Al mismo tiempo, se podría discutir la perspectiva irónica de la obra, asociada a la figura de inversión que constituyen las aves: "La ironía podría llamarse en el sentido propio del término, alegoría [...], porque piensa una cosa y, a su manera, dice otra"; "La ironía nos invita a realizar el movimiento intelectual [...] para adivinar las segundas intenciones, leer entre las líneas, comprender a medias palabras" (Jankélévitch, 1982: 40-59).

En resumidas cuentas, se denuncia el "iluminismo" de las aves de rapiña, porque "se llaman hidalgas, nobles, ilustres, ilustradas, cultas y civilizadas: como si fuera difícil a cualquiera el ilustrarse y civilizarse de este modo, vendiendo muy barata su inocencia y simplicidad, tirando sin conciencia a destruir a los demás para engordarse cada uno" (62); "en realidad son ladrones y homicidas, aunque se las pinten ilustradas, sabias, doctas, civilizadas" (78). Sobre esta sátira se debe recordar su deseo de un retorno a la Edad de Oro. Así, cualquier "progreso", sea científico, cultural, etc., es considerado como un peligro, lo que niega el principio mismo del Iluminismo. Se trata de una contra-utopía, porque rechaza una gran parte de las aspiraciones de la propia utopía del Iluminismo.

Hallamos en la obra nociones ilustradas sobre la moral (la defensa de la idea de virtud, la importancia de la felicidad, la igualdad, la educación, la sociabilidad, la razón, la política, la tolerancia y el derecho); pero se niegan los valores ilustrados de la civilización (la importancia de la ciencia) centrados en la formación de las academias (con el deseo del retorno a una Edad Primitiva) y el cosmopolitismo (con el miedo del extranjero). De acuerdo al ideal utópico, la falta tiene que ver mucho con la corrupción material de las aves: "se introdujo en ellas la gula y la lujuria, que tomaron del comercio con los avestruces del Asia, y comunicación con los papagayos Nordestes, y guacamayos de Indias" (63). Se ataca directamente la diferencia de riqueza entre las diferentes clases económicas y la política expansionista española, más preocupada por sus colonias y por el dinero que pudieran entregarle, que por lo que escondía la pretendida filosofía de la Ilustración.

Debemos recordar que el Iluminismo no contemplaba el beneficio de todos, ya que el Tercer Estado nunca tuvo acceso a los escritos filosóficos, como consecuencia del analfabetismo generalizado y de los problemas de supervivencia. Sarrailh (1957) habla de la "dolorosa existencia" de la masa rural por la falta de trabajo, las enfermedades, y, sobre todo, por "las cargas que pesan sobre los desdichados campesinos, los innumerables tributos que deben a 
los propietarios, a los distintos señores, eclesiásticos o civiles, y al Estado" (25). Esto concuerda con la avaricia de las aves de rapiña, representantes de la nobleza española dieciochesca. La construcción del país utópico representa una crítica indirecta -vía presentación de un contra-modelo- a lo que España debería orientarse, su "debeser": "el presentimiento objetivo de lo que todavía-no-ha-llegadoa-ser, en el sentido de lo que todavía-no-ha-llegado-a-ser-lo-quedebiera" (Bloch, 2004: 183).

Es criticada la reforma administrativa del Estado: "Tribunales mayores, como de Ministros, Virreyes y Consejeros, y de inferiores, como de Chancillerías, Audiencias, Intendencias, Gobiernos y Presidencias [...] Abogados, Relatores, Agentes, Escribanos, Alcaldes, Alguaciles, Verdugos y Pregoneros" (82), lo que en la obra lleva hacia una súper-organización, donde una vez más el beneficio es sólo de la clase dominante. En consecuencia, pasa revista a las limitaciones de la libertad individual: "que las palomas no fuesen tan absolutas dueñas de su vida" (81), lo que, paradójicamente, hace referencia a las propuestas del Iluminismo, como la idea de una libertad religiosa. Parece entonces que el Tratado sobre la monarquía columbina ocupa una posición mediana con la crítica de los valores propios del Iluminismo, y de una cierta forma de su aplicación práctica, y constata el fracaso moderado de la imposición de la Ilustración en España:

Tal programa de renovación económico-pedagógica, en paralelo a un proceso de centralización y racionalización administrativa -congruente con el advenimiento de una conciencia nacional unitaria-, no llegaría a cuestionar en ningún momento el marco estructural: sociedad estamental, confesionalismo católico, absolutismo monárquico. El relativo fracaso de las reformas -que chocaron con resistencias muy poderosas de un sector de la alta nobleza y el clero regular- y el aldabonazo de la Revolución precipitarán la crisis definitiva del sistema y la consiguiente dispersión de los ilustrados (Sebastián, 1998: 343).

\section{Conclusión}

La meta del Tratado sobre la monarquía columbina es claramente satírica. No obstante, se podría adjuntar una dimensión paródica, ya que, como vimos, la obra se constituye como una contra-utopía, utilizando los recursos propios del género utópico para mostrar su realización y 
su fracaso ${ }^{17}$. Una posición verdaderamente original a finales del siglo XVIII ante unas teorías iluministas más o menos bien instaladas en la sociedad española. Teorías que imponían una visión unilateral de la realidad. Como contracorriente, Merino propone un retorno a la Edad de Oro, delineando una inversión formal (la parodia del género utópico) y una subversión contextual (la sátira de una cierta modalidad del Iluminismo). Lo interesante es que mediante esta perspectiva satíricoparódica, el relato sigue interiorizando las propias bases del género utópico, pero transformándolas en un reflejo inverso al interior de un real proceso epistemológico crítico $^{18}$. En este sentido, la sátira paródica tiene entonces el papel de una "crítica literaria".

La figura satírica de las aves, considerada dentro de una perspectiva contra-utópica, permite pensar en la crítica de la sociedad española del siglo XVIII. Y si bien el Tratado sobre la monarquía columbina tiene una riqueza interpretativa relacionada con el uso alegórico de la figura de las aves, va más allá del lado agradable del procedimiento de la animalización. Abre su horizonte a la representación del modelo empírico del despotismo ilustrado y a una riqueza genérica: la coexistencia de los tratados de buen gobierno con la sátira paródica. Importa así abrir el camino hacia una nueva y mejor consideración de este tratado, pues, a pesar de la ausencia de una revisión crítica académica, la obra de Merino ofrece realmente una multiplicidad de posibilidades interpretativas. Las huellas dependerán solamente de la persona que quiera caminar y seguirlas durante más tiempo.

\section{Bibliografía}

Abellán, J. L. (1986). Historia crítica del pensamiento español, vol. III ("Del Barroco a la Ilustración: siglos XVII y XVIII"). Madrid: EspasaCalpe.

Anónimo. (1971). El fisiólogo: bestiario medieval. Buenos Aires: Universidad de Buenos Aires. (Traducción de Marino Ayerra Redín y Nilda Guglielmi. Introducción y notas de Nilda Guglielmi).

Aristophanes. (1996). "Les oiseaux". En Théâtre Complet. "Coll. Le Livre de Poche". France: Éditions Gallimard et Librairie Générale de France, vol. II, pp. 20-121. (Texte traduit, présenté et annoté par V.-H. Debidour).

\footnotetext{
${ }^{17}$ Constatando la desviación respecto al "canon utópico", comparando la obra, por ejemplo, con su doble utópico español: la Sinapia.

${ }^{18}$ Es decir, el movimiento crítico que empuja los propios límites de la literatura hacia la realización de todas sus posibilidades.
} 
Avilés Fernández, M. (Ed.). (1976). Sinapia: una utopía española del Siglo de las Luces. España: Editorial Nacional.

Bloch, E. (2004). El principio de esperanza. Madrid: Trotta. (Traducción de Felipe González Vicén).

Chevalier, J. \& Gheerbrant, A. (1982). Dictionnaire des symboles. "Coll. Bouquins". Paris: Robert Laffont/Jupiter.

Cooper, J.C. (2007). Diccionario de símbolos. España: Gustavo Gili. (Traducción de Enrique Góngora Padilla).

Ferrone, V. \& Roche, D. (Eds.). (1998). Diccionario histórico de la ilustración. España: Alianza. (Traducción de José Luis Gil Aristu).

Jankélévitch, V. (1982). La ironía. España: Taurus. (Traducción de Ricardo Pochtar).

Malaxecheverría, I. (1999). Bestiario medieval. España: Siruela.

Mannheim, K. (1941). Ideología y utopía. Introducción a la sociología del conocimiento. México: Fondo de cultura económica. (Traducción de Salvador Echavarría).

Merino de Jesucristo, A. (1790). Tratado sobre la monarquía columbina. En Valladares de Sotomayor. (Comp.). Semanario erudito que comprehende varias obras inéditas, criticas, morales, instructivas, políticas, históricas, satíricas, y jocosas de nuestros mejores autores antiguos y modernos, vol. XXIX, Madrid, pp. 61-84.

Platón. (2006). La República. España: Centro de Estudios Políticos y Constitucionales. (Edición bilingüe, traducción, notas y estudio preliminar por José Manuel Pabón y Manuel Fernández-Galiano).

Saavedra Fajardo, D. Las empresas políticas. Idea de un príncipe políticocristiano representada en cien empresas. (2vol). Buenos Aires: Sociedad de Ediciones Louis-Michaud.

Sarrailh, J. (1957). La España ilustrada de la segunda mitad del siglo XVIII. México: Fondo de Cultura Económica.

Sebastián, S. (1995). Emblemática e historia del arte. España: Cátedra.

Truman, R.W. (1999). Spanish treateses on government, society, and religion in the time of Philip II: the "De regimine principum" and associated traditions. Leiden: Brill. 
